\title{
Combined Effects of Geometric and Material Non-linearities on One Dimensional Structural Members
}

\author{
R.Ramgopal Varma \\ Dept.of Manufacturing Engineering \\ Faculty of Technology, Universiti Malaysia Pahang, \\ Lebuhraya Tun Razak, 26300 Gambang, Kuantan, \\ Pahang, Malaysia \\ ramgopal@ump.edu.my
}

\begin{abstract}
Combined effects of geometric and material nonlinearities on a uniform column subjected to an axial compressive load are presented in the present note. A simple, direct iterative numerical method has been proposed to study the geometric and material non-linear behavior of columns subjected to varying boundary conditions. Introduction of material non-linearity in the large deflection analysis of columns subjected to an axial compressive load reveals a reduction in Euler stress obtained when compared to the effect of geometric non-linear analysis and increase in the same when compared to the effect of material non-linear analysis. $A$ convergence study has been carried out for the results obtained from the proposed iterative method to prove the efficacy.
\end{abstract}

Index Terms-Geometric and Material Nonlinearities, Combined effect, Structural Members

\section{INTRODUCTION}

Structural members like columns find their application in many components of structural assemblies. Generally slender cantilever columns are widely used as struts carrying compressive loads. Analysis of the structural members as close to reality as possible will serve the purpose in attaining meaningful results. The elastic analysis of the columns subjected to compressive loads has been studied by many researchers and reported in Ref. [1]. The analysis of columns of uniform cross section subjected to tip concentrated loads has been investigated by in the study [1] by using elliptical integrals. An approximate solution of the problem with exponentially varying flexural rigidity has been studied Bhandari [2]. A numerical solution of the large deflection analysis of uniform columns uniformly distributed load has been investigated in the studies of Holden [3]. Rao and Raju[4], have made an attempt by using the Galerkin finite element method to obtain the solution for elastic buckling behavior of uniform column. It is clear from the analysis that the effect of geometric non-linearity is one of hardening type.

The stresses and strains in column subjected to axial loads are high and make the stress-strain relationship nonlinear, hence this effect on the stress- strain relationship has to be taken into account. Similar studies have been reported in Olden and Childs [5], where the inelastic post buckling of columns has been studied by considering the effect of a hyperbolic moment - curvature relationship for the cross section of the column. The unloading that occurs at the convex face of the straight column when it bends has been neglected in this study. With an assumption that the axial stress is negligible compared to the bending stress [6], Monasa studied the elasto-plastic buckling of bars

\author{
G Venkateswazra Rao \\ Research Professor, \\ Sreenidhi Institute of Science and Technology, Hyderabad, \\ India.501 301 \\ hydrao1944@yahoo.co.in
}

using moment - curvature nonlinear relations. In the study of large deflection analysis of elastic columns to an uniformly distributed load by Nageswara Rao and GV Rao [7], the combined effects of geometric and material nonlinearities have been considered. A uniform column subjected to a uniform compressive load is considered and the solution is obtained by a simple and accurate numerical scheme. Similar study on large deflection analysis of elasto-plastic columns subjected to uniform compressive loads has been reported in Ref.[8]. However, in all the studies reported earlier, the solution procedure by higher mathematics or solution by elliptical integrals. Hence, an attempt has been made in the present note to study the combined effects of the geometric and material nonlinearities by using a Galerkin method and RambergOsgood type formula [9] for geometric and material nonlinearities respectively. The results were obtained in the present study by a simple iterative method. The convergence study of the results has been carried out to prove the accuracy of the results from the present investigation.

\section{FORMULATION OF THE PROBLEM}

A cantilever column as shown in Fig.1, of length $l$ is subjected to an uniform compressive load P. Due to this compressive load, the column undergoes large deflections as shown. It is required to determine Euler buckling stress of the column for a given tip deflection $\alpha$.

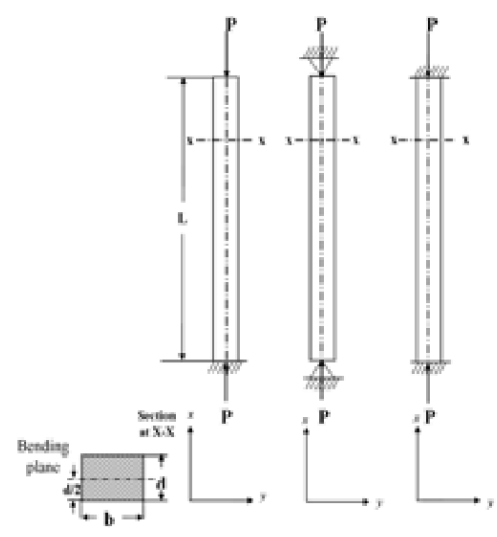

Fig 1 Shows the rectangular cross section of cantilever, simply supported and clamped column subjected to uniform Compressive load 


\section{PROPOSED ITERATIVE METHOD}

The present investigation aims in proposing a simple, direct and completely analytical iterative method. The governing non-linear differential equation for the geometric nonlinear behavior of the column is obtained from the moment curvature relationship as

$$
\theta^{\prime \prime}+\lambda \sin \theta=0 \quad 1
$$

By Galerkin method, Eq.(1) becomes

$$
\theta^{\prime \prime}+\lambda \sin \theta=\varepsilon
$$

where." denotes double differentiation with respect to $\xi$ and $\theta=a \sin \left(\frac{\pi \xi}{2}\right), \quad \theta=a \sin Q \pi \xi_{-}^{-}$and $\theta=a \cos \pi \xi^{-}$for cantilever, clamped and simply supported columns respectively. $\xi=\mathrm{s} / l$, represents the coordinate transformation, and $l$ is the length of the column.

From Eq.(1), we can write

$$
\int_{0}^{1} \sin \frac{\pi \xi}{2} \varepsilon d \xi=0
$$

Expanding the sine series we have

$$
\begin{gathered}
\sin \theta=\left[\theta-\frac{\theta^{3}}{3 !}+\frac{\theta^{5}}{5 !}-\frac{\theta^{7}}{7 !}+\cdots-----\right] \\
=\theta\left[1-\frac{\theta^{2}}{3 !}+\frac{\theta^{4}}{5 !}-\frac{\theta^{6}}{7 !}+--------\right] \\
=\theta\left[\boldsymbol{F}_{-}^{-}\right.
\end{gathered}
$$

Substituting value ' $\theta$ ' for cantilever we have

$$
\begin{aligned}
& \int_{0}^{1} \sin \left(\frac{\pi \xi}{2}\right)\left(\frac{-a \pi^{2}}{4} \sin \left(\frac{\pi \xi}{2}\right)\right)+ \\
& \lambda \operatorname{asin}\left(\frac{\pi \xi}{2}\right) \sin \left(\frac{\pi \xi}{2}\right) F \theta=0 \\
& \text { From Eq.(6), } \lambda=\frac{\frac{\pi^{2}}{4} \int_{0}^{1} \sin ^{2}\left(\frac{\pi \xi}{2}\right) d \xi}{\int_{0}^{1} F \boldsymbol{\operatorname { s i n }} 2\left(\frac{\pi \xi}{2}\right) d \xi} \quad 7
\end{aligned}
$$

where $\lambda$, is the critical load parameter ie. $\frac{P_{c} l^{2}}{E I}$ where $\mathrm{E}$ is the Young's modulus, $l$ is the length of the column I is the moment of inertia and $\mathrm{P}_{\mathrm{c}}$ is the critical load.

Similarly, critical load parameters for the other two boundary conditions of the beam/column could be obtained as

$$
\begin{aligned}
& \lambda=\frac{4 \pi^{2} \int_{0}^{1} \sin ^{2}(\pi \xi) d \xi}{\int_{0}^{1} F \otimes \sin ^{2}(\pi \xi) d \xi} 8 \\
& \lambda=\frac{\pi^{2} \int_{0}^{1} \cos ^{2}\{\xi g \xi}{\int_{0}^{1} F \boldsymbol{\theta} \cos ^{2}\{\xi) d \xi} \quad 9
\end{aligned}
$$

to clamped and simply supported boundary conditions respectively.

To account for the material non-linearity,

Ramberg-Osgood Type [9] formulation, has been used in many researches [10]. However, for the sake of completeness the formula representing the stress - strain curve is represented by

$$
\varepsilon=\frac{\sigma}{E}+K\left(\frac{\sigma}{E}\right)^{n}
$$

where $\varepsilon$ is the strain, $\sigma$ is the stress, E is the Young's modulus, $\mathrm{K}$ is a constant and $\mathrm{n}$ is an integer which are obtained by a least squares curve fitting technique.

The critical buckling load parameter of the column subjected to both geometric and material non-linearities is given by

$$
\sigma_{c g}=\gamma \cdot \frac{E}{\left(\frac{l}{r}\right)^{2}}
$$

where, $\gamma$ is the value obtained from integrating the geometric non-linear behavior of column for each tip deflection parameter. $l / r$ is the slenderness ratio of the column with $l$ as length and $\mathrm{r}$ as radius of gyration.

The value of $\gamma$ are given by Eqs.(7), (8) and (9) for cantilever, clamped and simply supported boundary conditions respectively.

The tangent modulus is obtained by differentiating the Eq.(10) with respect to $\sigma$, as

$$
E_{t}=E /\left\{1+7 . K \cdot\left(\frac{\sigma_{c g}}{E}\right)^{6}\right\}
$$

A direct iterative procedure is applied to evaluate the values of $E_{t}$ is given as follows 
1. For the column configuration considered find the Euler buckling stress due to the effect geometric and material non-linearity by Eq.(11).

2. From the stress obtained in step (1) find the value of $E_{t}$ from Eq.(12).

3. Replace $E$ by $E_{t}$ and evaluate new $\sigma_{c g}$ stress for specific value of $\alpha$, tip deflection angle for the boundary condition considered.

4. Repeat steps 1 to 3 till the converged value of $\mathrm{E}_{\mathrm{t}}$ stress is obtained.

Update the tip deflection angle $\alpha$ in the geometric nonlinear term $\gamma$, and repeat the procedure for converged $E_{t}$ stress as in steps 1 to 4 , for different slenderness ratios and tip angles.

\section{NUMERICAL RESULTS}

The proposed iterative method is used to study the combined effects of geometric and material non-linear behavior of columns to an axial compressive load. The material of the column is taken as 24ST aluminium alloy as in previous studies. The empirical results for the three boundary conditions considered are presented in the form of tabular columns. The results for a cantilever column subjected to an axial compressive load for various tip deflection angles and slenderness ratios are presented in table 1. It can be seen that columns with high slenderness ratios the effect of non-linear effects is not much felt due to the boundary condition of the column considered. However, when the slenderness ratio decreases and the tip angle increases, the effect of the elasto-plastic buckling is clearly seen. The effect of geometric non-linearity and material non-linearity itself are also presented in this table for the better understanding.

In table 2 and 3 , the results obtained from the present investigation to simply supported and clamped boundary conditions of the column are presented. The effect of nonlinearities is clearly seen in these tables for the other slenderness ratios. A convergence study has been carried out by the proposed iterative method to prove the efficacy of the proposed simple formulation.

Table 1 Values of Euler Stress in kpa for a Cantilever Column for Varying Tip Deflections and Slenderness Ratios

\begin{tabular}{|c|c|c|c|c|}
\hline$u r$ & $\begin{array}{l}\alpha \text { in } \\
\text { deg }\end{array}$ & $\begin{array}{l}\text { Effect of Material } \\
\text { neetlinearity }\end{array}$ & 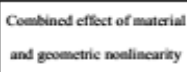 & $\begin{array}{c}\text { Effost of goouestric } \\
\text { nonlinezity }\end{array}$ \\
\hline \multirow{4}{*}{200} & 20 & \multirow{4}{*}{4.6230} & 4.6941 & 4.6941 \\
\hline & 40 & & 4.9166 & 4.9166 \\
\hline & 80 & & $5.31 \%$ & 5.3196 \\
\hline & 50 & & 5.9628 & 5.9628 \\
\hline \multirow{4}{*}{100} & 20 & \multirow{4}{*}{18.4922} & 18.7767 & 18.7767 \\
\hline & 40 & & 19.6662 & 19.6662 \\
\hline & 60 & & 21.2787 & 21.2787 \\
\hline & 80 & & 23.8511 & 23.8511 \\
\hline \multirow{4}{*}{50} & 20 & \multirow{4}{*}{73.9143} & 75.0463 & 75.1068 \\
\hline & 40 & & 78.5813 & 78.6649 \\
\hline & 60 & & 84.9704 & 85.1150 \\
\hline & 80 & & 95.0568 & 95.4045 \\
\hline
\end{tabular}

Table 2 Values of Euler Stress in kpa for a Simply Supported Column for Varying Tip Deflections and Slenderness Ratios

\begin{tabular}{|c|c|c|c|c|}
\hline$u r$ & $\begin{array}{l}\alpha \text { in } \\
\text { deg }\end{array}$ & $\begin{array}{l}\text { Eflitest of Material } \\
\text { nonilinterily }\end{array}$ & 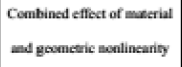 & 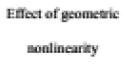 \\
\hline \multirow{4}{*}{200} & 20 & \multirow{4}{*}{18.4922} & 18.7767 & 18.7767 \\
\hline & 40 & & 19.6662 & 19.6662 \\
\hline & 60 & & 21.2787 & 21.2787 \\
\hline & 80 & & 23.8511 & 23.8511 \\
\hline \multirow{3}{*}{100} & 20 & \multirow{3}{*}{73.9143} & 75.0463 & 75.1065 \\
\hline & 40 & & 78.5813 & 78.6649 \\
\hline & 80 & & 95.08686 & 95.4045 \\
\hline \multirow{4}{*}{75} & 20 & \multirow{4}{*}{128.836} & 130.5945 & 133.523 \\
\hline & 40 & & 135.965 & 139.848 \\
\hline & $\infty 0$ & & 145.172 & 151.315 \\
\hline & 80 & & 158. 331 & 169.608 \\
\hline
\end{tabular}

Table 3 Values of Euler Stress in kpa for a Clamped Column for Varying Tip Deflections and Slenderness Ratios

\begin{tabular}{|c|c|c|c|c|}
\hline$\nu r$ & $\begin{array}{l}\alpha \text { in } \\
\text { deg }\end{array}$ & $\begin{array}{l}\text { Effiest of Material } \\
\text { nowlinerarity }\end{array}$ & 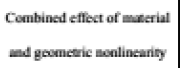 & $\begin{array}{l}\text { Efflect of goometeic } \\
\text { monlinearity }\end{array}$ \\
\hline \multirow{4}{*}{200} & 20 & \multirow{4}{*}{73.9143} & 75.0463 & 75.1068 \\
\hline & 40 & & $76.5 \$ 13$ & 78.66649 \\
\hline & 60 & & 84.9704 & 85.1150 \\
\hline & 80 & & 95.6668 & 95.4045 \\
\hline \multirow{4}{*}{175} & 20 & \multirow{4}{*}{96.2659} & 97.7143 & 98.0988 \\
\hline & 40 & & 102.218 & 102.746 \\
\hline & 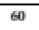 & & 110.274 & 111.1706 \\
\hline & 30 & & 1122.715 & 124.609 \\
\hline \multirow{4}{*}{150} & 20 & \multirow{4}{*}{128.836} & 130.5945 & 133.523 \\
\hline & 40 & & 135.965 & 139.848 \\
\hline & 60 & & 145.172 & 151.315 \\
\hline & 80 & & 158.731 & 169.6008 \\
\hline
\end{tabular}

\section{CONCLUSIONS}

In the present paper a simple, direct iterative numerical method has been proposed to investigate the combined effects of geometric and material non-linearities for the columns of various boundary conditions subjected to an axial compressive load. The effect of non-linearities is clearly presented in the present note for various slenderness ratios and tip deflection angles of the column.

\section{ACKNOWLEDGMENT}

The authors are thankful to the respective management and institutes for the constant encouragement during the course of this work. 


\section{REFERENCES}

1. Timoshenko, S.P., and Gere, J.M., 1961, Theory of Elastic Stability, McGraw - Hill, Tokyo.

2. Bhandari, R.G., 1967, "Large Deflection of Columns of Variable Flexural Rifgity”, AIAA Journal, Vol.5, 1486-1488.

3. Holden, J.T., 1972, "On finite deflection of Thin Beam", International Journal of Solids and Structures, Vol.8, 1051-1055.

4. Rao, G.V., and Raju, P.C., 1977, "Postbuckling of Uniform Cantilever Columns - Galerkin Finite Element Solution", Engineering Fracture Mechanics, Vol.9, pp.1-4.

5. Oden, J.T., and Childs, S.B., 1970, "Finite Deflection of a nonlinear Elastic bar", Journal of Applied Mechanics, ASME, Vol.37, pp.4852

6. Monasa, F.E., 1974, "Deflections and Stability of Elasto-Plastic flexible bars", Journal of Applied Mechanics, ASME, Vol.41, pp.537-538
7. Nageswara Rao, B., and Rao.G.V., 1989 "Large Deflection Analysis of Elasto-plastic Columns Subjected to a Compressive Load”, Res. Mechanica, Vol.26, pp.19-34

8. Nageswara Rao, B., and Rao.G.V., 1989 "Post-Buckling Analysis of a Uniform Cantilever Column Subjected to a Tip concentrated Sub tangential Follower Force", Forschung im Ingenieurwesen, Vol.55, No.2. pp.36-38.

9. Ramberg, W. and Osgood, W.R., 1943 "Description of stress-strain curves by three parameters", NACA TN 902.

10. Varma R.R.G, Rao.G.V, "Study of the inelastic buckling behavior of columns including transverse shear deformation"Journal of Structural Engineering (JOSE)- CSIR, India Vol. 37, No. 4, October, 2010 pp.296-298. 